\title{
Assessment of Neurodevelopment of Infants of Diabetic Mothers 6 Year Follow-up
}

\section{Jiménez-Quiroz Rosalía ${ }^{1 *}$, López-Vasquez Ethel ${ }^{2}$, Alvarez-Ramírez Elizabeth $^{3}$, Conde-Reyes María de la Paz ${ }^{1}$, Romero-Palencia Angélica ${ }^{4}$, Fernández-Carrocera Luis Alberto ${ }^{5}$, Guido-Campuzano Martina Angélica $^{6}$, Castro-Soto Laura ${ }^{7}$ and Martínez-Cruz Carlos Fabián ${ }^{8}$}

${ }^{1}$ Psychology, Department of Pediatric Follow-up, National Institute of Perinatology, Mexico City, Mexico

${ }^{2}$ Rehabilitation, Early Treatment, Lighten Blindness and Low Vision Foundation, Mexico City, Mexico

${ }^{3}$ Educational Psychology, National Pedagogical University. Social Psychology Faculty of University Studies, National Autonomous University, Mexico City, Mexico ${ }^{4}$ Institute of Health Sciences, Autonomous University of the State of Hidalgo, Pachuca, Hidalgo, Mexico

${ }^{5}$ Neonatal Intensive Care Unit, National Institute of Perinatology, Mexico City,

Mexico

${ }^{6}$ Neonatology, Department of Pediatric Follow-up, National Institute of Perinatology, Mexico City, Mexico

${ }^{7}$ Neonatologist, Resident of the Diploma Course of Neurodevelopment of the High-risk Newborn, National Institute of Perinatology, Mexico City, Mexico ${ }^{8}$ Human Communication, Department of Pediatric Follow-up, National Institute of Perinatology, Mexico City, Mexico

*Corresponding Author: Jiménez-Quiroz Rosalía, Psychology, Department of Pediatric Follow-up, National Institute of Perinatology, Mexico City, Mexico.
Received: February 26, 2021

Published: March 22, 2021

(C) All rights are reserved by Jiménez-Quiroz Rosalía., et al.

\begin{abstract}
The infant of a mother with gestational diabetes (IDM) is a newborn with high neurological risk and can not ensure an evolutionary pattern in his neurodevelopment; therefore, he must be monitored during the first years of life. The objective of this research is to describe the neurodevelopment of infants of mothers with gestational diabetes at 1 - 6 years of age born in the National Institute of Perinatology, through a retrospective longitudinal study. The sample consisted of 46 participants; 17 boys and 29 girls, children of mothers with gestational diabetes born between 2000 and 2010, who were assessed with the Bayley II Development Scale at the first and second years of life and the Stanford-Binet Intelligence Scale $4^{\text {th }}$ ed. at the $3^{\text {rd }}, 4.5$ and 6 years. The results show that IDM have a slight delay in the Psychomotor Developmental Index in the first two years that does not affect scores in the Intellectual Quotient at 3-6 years, obtaining scores within the normal range.
\end{abstract}

Keywords: IDM; Gestational Diabetes; Neurodevelopment; MDI; PDI; Intellectual Quotient; Cognitive Development

Citation: Jiménez-Quiroz Rosalía., et al. “Assessment of Neurodevelopment of Infants of Diabetic Mothers 6 Year Follow-up”. Acta Scientific Women's Health 3.4 (2021): 10-19. 


\section{Introduction}

Infants of mothers with gestational diabetes (IDM) have been the object of studies due to complications during pregnancy and birth, considering them newborns with a high neurological risk. According to the National Confederation of Pediatrics in Mexico [1] they are children with more probabilities of presenting developmental impairments, which may be cognitive, motor, sensory or behavioral.

Studies on neurodevelopment of IDM report that, not only due to their birth condition and their genetic load, but also the influence of the environment, there are differences in neurodevelopment compared to infants born to healthy mothers. Nevertheless, knowing the degree of impairment depends on multiple individual and environmental factors, from the mother's pregnancy to the child's adult life $[2,3]$.

The concept of neurodevelopment involves a multifactorial process that generates and expresses itself on the interactions of people with their environment; in other words, it is the result of the intersection of genetic and sociocultural factors and can be understood as the development manifested as of the development of the brain as a whole. It is defined by Gutiérrez., et al. [5] as the external manifestation of the maturity of the nervous system, which starts very early in intrauterine life and continues many years after birth.

In the appropriate context, the assessment of neurodevelopment allows for an estimation of what is happening in brain development. Identifying the risk of brain damage, as expressed by neurodevelopmental impairments, allows for an intervention. The faster the proper stimulation is provided, the better the utilization of brain plasticity and other benefits; in some cases de consequences will be minor [2,5]. Early intervention includes the processes of prevention, diagnosis and intervention, with the objective of enhancing the infant's abilities so that he can be integrated adequately into society [6]. One of the more widely used tools to monitor neurodevelopment is the measurement of physical growth and nutritional status; nevertheless, appropriate agebehaviors also define a normal development [3]. Psychological test batteries help to compare observed behavior with expected behavior, thus quantifying development achieved [5,7]. There are different tests applied during the first years of life, such as Battelle (Battelle Developmental Inventory), DENVER, EDI (Infant Development Scale), and the Bayley Scale of Infant Development (BSID), used in clinical research. On the other hand, in school-age children intelligence tests are used, such as Wechsler, Stanford-Binet and Kaufman Brief Intelligence Test, amongst others, assessing different abilities of cognitive development [8]. The decision to use one test or another is based on the resources available and the profile of the examiner [5].

\section{The infant of a mother with gestational diabetes}

A history of gestational diabetes represents a risk factor for the evolution of diabetes mellitus type 2 , arterial hypertension, obesity and metabolic syndrome in the mother as well as the child. Due to the fact that gestational diabetes creates a sub-optimal environment associated with high levels of glucose, IDM are characterized by neurological impairments and consequentially, cognitive impairments $[2,3,9,10]$.

Most neurological dysfunctions occur during the second half of pregnancy, and may consequentially damage migration processes, cellular differentiation, cortical neuron stratification, myelinization and synapses formation. Deficits in cognitive functions have been observed in relation to the hippocampus, structure in charge of memory and vulnerable to chronic hypoxia and iron deficits [11].

Studies have mainly focused on genetic malformations and on interventions during the neonatal period, where it has been observed that IDM have an abnormal neurological development [12], leading to suspect that this condition may have long-term adverse effects.

Infants have shown a normal psychomotor developmental and mental index at two years, but compared to infants of healthy mothers, these indexes turn out lower [13]. In later years, when assessing cognitive development through intelligence and neuropsychological tests, Bolaños., et al. [14] describe a tendency in IDM to present a lower level of intelligence and a greater number of perseverative answers, which explains the lack of cognitive flexibility regarding the ability to adapt to environmental changes, and a lower performance in tasks related to graphic abilities, related to a deficit in fine motor skills. Temple., et al. [15] found in his studies lower scores in working memory, Dionne., et al. [16] in expressive language and Ornoy [11] a greater amount of mild neurological signs. Although low scores are reported for the aforementioned areas, they are mostly not statistically significant when compared with control groups $[9,14,17,18]$. 
Nielsen., et al. [19], Ornoy [11], Ratzon [20] have considered the normal intelligence scores in IDM to be the result of a better glycemic control during pregnancy; it has been found that the earlier the detection, the better the outcomes will be for the health of the mother-child binomial [2].

Other studies underpin that a good cognitive performance is the result of shared family characteristics such as socioeconomic level and educational level of the parents $[21,22]$, more than intrauterine causes during gestation. This could contrast with studies revised by Vargas-Rubilar and Arán-Filippetti [23] that consider upbreeding patterns, stimulation, family climate and attachment all influence in children's better cognitive development.

In the neurobehavioral area, it has been observed that IDM have a greater prevalence of Attention Deficit Hyperactivity Disorder (ADHD). This is a disorder characterized by a persistent pattern of inattention, hyperactivity or impulsivity that interferes with academic activity, family and social environment. Studies in IDM report ADHD occurs more frequently in populations with a low socioeconomic level [17], although these attention problems do not have a negative impact on intelligence scores [18].

Different studies have tried to describe and explain consequences of IDM in neurodevelopment, finding low intelligence scores when compared to healthy children; however, these intelligence scores may be normal in IDM [15,24].

The study of neurodevelopment in IDM in Mexico is very scarce because of methodological limitations, and the few studies existing today focus their perspective on comorbidities at birth; however there is a lack of longitudinal studies that offer scientific evidence on neurodevelopment in IDM $[14,21]$.

\section{Objective of the Study}

The objective of this study is to describe the neurodevelopment of infants of mothers with gestational diabetes from 1-6 years of age born at the National Institute or Perinatology.

\section{Materials and Methods}

Due to the lack of information on long-term neurodevelopment of IDM in Mexico, this study is considered exploratory, limited to describing the dimensions of neurodevelopment. The sample was comprised of 46 participants; 17 male and 29 female, all children of mothers with gestational diabetes, born between 2000 and 2010 at the National Institute of Perinatology and participating in the Pediatric Follow-up program. Being a longitudinal, retrospective, cohort design, these infant's neurodevelopment was assessed annually, the first assessment being at one year of age, followed by a second assessment at two years of age, and successively until 6 years of age.

\section{Instruments}

The instruments used to measure neurodevelopment are: 1) Bayley II Scale of Infant Development (1993) [25]: assesses the development of children from 1 to 42 months of age and consists of a mental scale and a psychomotor scale. The Mental Scale: assesses memory abilities, habituation, problem solving, numerical concepts, generalization, classification, vocalization and language skills, social skills, among others; it has a reliability of 0.75 to 0.93 . The Psychomotor Scale assesses the control of thick and thin muscle groups, with a reliability of 0.65 to 0.90 . The results of the Mental Scale as well as the Psychomotor Scale are expressed in typical scores or Developmental Indexes that present a mean of 100, with typical deviations of 16 and 15, respectively, and are classified in the following way: 116 or greater: Accelerated development; 85115 Within normal limits; 70-84 Mild delay in development; 69 or less: Significant delay in development.

Stanford Binet Intelligence Scale $4^{\text {th }}$ Ed. By Terman Merril (Thorndike, Hagen and Santler, 1986) [26]: used from 2 to 23 years of age, with a reliability of 0.91 with an IQ less than 0.70 and 0.90 for an IQ greater than 129. Made up of four areas:

- Verbal reasoning: Assesses word knowledge, verbal comprehension, cultural or family history, social judgment and common sense, knowledge of conventional norms, practical judgment and knowledge of the environment.

- Visual abstract reasoning: Assesses hand-eye coordination, visual spacial integration and comprehension, ability to analyze and synthesize.

- Numerical reasoning: Assesses the ability to apply numerical reasoning to problem solving, concentration, attention, short term memory and perception.

- Short term memory: Assesses visual and auditory memory, involving attention and concentration.

- Standardized classification by area and total scores by areas: > 132 Very superior, 121 - 131 Superior, 111 - 120 High Average, 89 - 110 Average, 79 - 88 Low Average, 68 - 78 Slow learning, $\leq 67$ Mental retardation. 


\section{Process}

The review was made from the hospital database by locating 236 IDM that were seen at the pediatric follow-up, revising the 236 clinical files in order to capture data and verifying the diagnosis of diabetes, and that the children had attended their first appointment to psychology at one year of age, two years of age and consecutively until six years of age. At the end the sample consisted of 46 participants; 17 male and 29 female, who attended all their yearly assessments. Data was taken from their file including results from the Bayley II Scale of Infant Development and the Stanford Binet Intelligence Scale, date of birth, weeks of gestation, weight at birth, medical complications at birth, mother's age and sociodemographic data.

\section{Results}

The results are presented in three sections. The first includes sociodemographical data of the family of the IDM. The second includes the results related to the birth of the IDM and the third includes neurodevelopmental results.

\section{Sociodemographic data}

The mean age of the mother's pregnancy was 35.7 years $(\mathrm{SD}=$ 6.7). $70 \%$ of the sample were singleton pregnancies, followed by $17 \%$ twin pregnancies and $13 \%$ triplets. Sociodemographical data of the families of IDM are shown on table 1.

The mean weight of IDM at birth was 1703g (SD $=656)$ and for the weeks of gestation the median was 33 (DE $=3$ ). These are classified as shown in table 2 , where it can be observed that almost $89 \%$ are males that did not reach 37 weeks of gestation and $50 \%$ had a birth weight less than $1500 \mathrm{~g}$.

Concerning comorbidities of IDM at birth, the most significant ones are metabolic disorders including hypoglycemia, hyperglycemia and hypocalcemia; however in this population there was a low incidence. Pulmonary pathology including respiratory distress syndrome, transient tachypnea of the newborn, pneumonia, atelectasis, among others, followed by multifactorial hyperbilirubinemia and intrauterine growth restriction were more frequent. Bronchopulmonary dysplasia, periventricular leukomalacia and perinatal asphyxia occur in a smaller percentage as shown in graph 1 . Given the average number of diseases of $4 \pm 2$, it is necessary to point out that each infant could present one or more of these comorbidities, the minimum being one and the maximum eleven.

Pertaining to neurodevelopment, children were assessed at one and two years by the Bayley II Scale of Infant Development and at

\begin{tabular}{|c|c|c|}
\hline & $\mathbf{n}$ & $\%$ \\
\hline \multicolumn{3}{|c|}{ Mother's level of education } \\
\hline None & 3 & (7) \\
\hline Elementary & 15 & (33) \\
\hline Middle school & 20 & (43) \\
\hline High school & 8 & (17) \\
\hline Bachelor & 8 & (17) \\
\hline \multicolumn{3}{|l|}{ Father's level of education } \\
\hline None & 5 & (9) \\
\hline Elementary & 7 & (16) \\
\hline Middle school & 12 & $(26)$ \\
\hline High school & 13 & (29) \\
\hline Bachelor & 9 & $(20)$ \\
\hline \multicolumn{3}{|l|}{ Mother's occupation } \\
\hline Housewife & 31 & $(67)$ \\
\hline Commerce & 5 & (11) \\
\hline Trade & 3 & $(6)$ \\
\hline Professional & 8 & (16) \\
\hline \multicolumn{3}{|l|}{ Father's occupation } \\
\hline Commerce & 5 & (11) \\
\hline Trade & 27 & $(65)$ \\
\hline Professional & 11 & $(24)$ \\
\hline Not known & 3 & (6) \\
\hline \multicolumn{3}{|l|}{ Type of family } \\
\hline Nuclear & 15 & (33) \\
\hline Nuclear Three generation & 16 & $(35)$ \\
\hline Single parent & 9 & (19) \\
\hline Rebuilt & 4 & (9) \\
\hline Other & 2 & (4) \\
\hline \multicolumn{3}{|l|}{ Planned pregnancy } \\
\hline Yes & 24 & (52) \\
\hline No & 21 & $(48)$ \\
\hline \multicolumn{3}{|l|}{ Pregnancy number } \\
\hline 1 & 22 & $(48)$ \\
\hline 2 & 12 & (26) \\
\hline 3 & 8 & (17) \\
\hline 4 & 4 & (9) \\
\hline \multicolumn{3}{|l|}{ Loss of pregnancy } \\
\hline 0 & 30 & (61) \\
\hline 1 & 10 & (26) \\
\hline 2 & 6 & (9) \\
\hline
\end{tabular}

Table 1: Sociodemographic data of the family of IDM $(n=46)$. 


\begin{tabular}{|l|c|c|}
\hline & N & \% \\
\hline Weight & & \\
\hline$\leq 1000 \mathrm{~g}$ & 6 & $(13)$ \\
\hline $1001-1500 \mathrm{~g}$ & 17 & $(37)$ \\
\hline $1501-2500$ & 18 & $(39)$ \\
\hline$\leq 2501$ & 5 & $(11)$ \\
\hline Weeks of gestation & & \\
\hline$\leq 28$ & 3 & $(7)$ \\
\hline $28.1-33.6$ & 19 & $(41)$ \\
\hline $34-36.6$ & 18 & $(39)$ \\
\hline$\leq 37$ & 6 & $(13)$ \\
\hline
\end{tabular}

Table 2: Weight at birth and weeks of gestation of Infants of mothers with gestational diabetes (IDM) $(n=46)$.

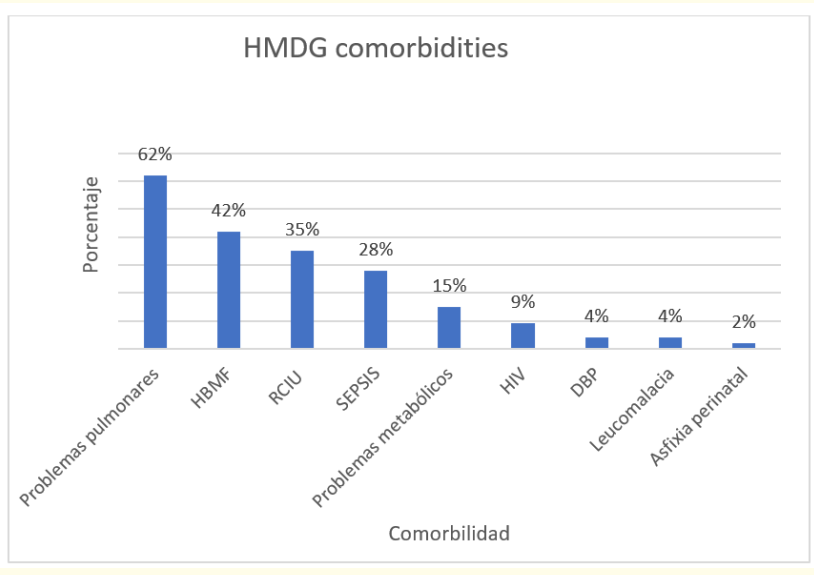

Graph 1: Comorbidities in IDM.

Note: Pulmonary pathology (Respiratory distress syndrome, Transient tachypnea of the newborn, Membrane hyaline disease) MFHB: Multifactorial Hyperbilirubinemia; IUGR: Intrauterine Growth Restriction; IVH: Intraventricular Hemorrhage; BPD: Bronchopulmonary Dysplasia.

three and six years by the Stanford-Binet Intelligence Test by Terman Merril, reporting the following data.

According to the classification by Bayley II, during the first year of life there was a normal Mental Developmental Index (MD) reported for most cases; the Psychomotor Developmental Index
(PDI) is located in the category of Mild Developmental Delay. At two years most children are located in the range of Mild Developmental Delay for both Mental (MDI) and Psychomotor (PDI) indexes. From three to six years the Intellectual Quotient is found more commonly within average (See graph 2).

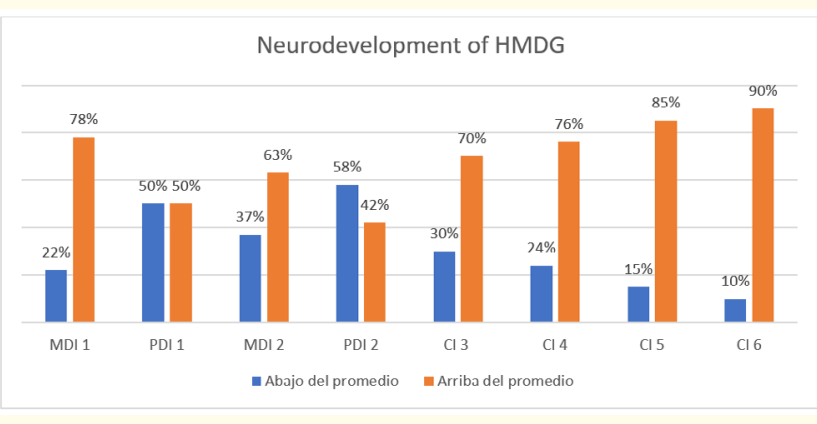

Graph 2: Neurodevelopment in IDM.

Note: $\mathrm{n}=46$, MDI1: Mental developmental index at 1 year; PDI1: Psychomotor developmental index at one year; MDI2: Mental developmental index at 2 years; PDI2: Psychomotor developmental index at 2 years; IQ 3: Intellectual quotient at 3 years of age; IQ 4: Intellectual quotient at 4 years of age; IQ 5: Intellectual quotient at 5 years of age; IQ 6: Intellectual quotient at 6 years of age.

As observed in table 3, MDI for the first year presents a greater mean in relation to PDI. During the second year, the MDI mean decreases in relation to the first year and PDI stays the same, with low scores that classify as mild developmental delay.

\begin{tabular}{|l|c|c|}
\hline & 1 year & 2 years \\
\hline & $\mathbf{M} \pm \mathbf{S} \mathbf{D}$ & $\mathbf{M} \pm \mathbf{S} \mathbf{D}$ \\
\hline $\mathrm{MDI}^{\mathrm{a}}$ & $91.87 \pm 17.9$ & $84.48 \pm 17.3^{*}$ \\
\hline $\mathrm{PDI}^{\mathrm{b}}$ & $79.07 \pm 18.4^{*}$ & $80.98 \pm 20.2^{*}$ \\
\hline
\end{tabular}

a: MDI Mental developmental index; b: PDI psychomotor developmental index; *: Mild developmental delay.

Table 3: Average mental and psychomotor developmental indexes in IDM at one and two years of age.

Regarding IQ for 3 - 6 years, a tendency to increase can be observed in scores as well as IQ, just as in the areas it comprises. The lowest means are for Visual Abstract Reasoning and Numerical Reasoning at three years of age (See table 4). 


\begin{tabular}{|l|c|c|c|c|}
\hline & 3 years & 4 years & 5 years & 6 years \\
\hline & M \pm S D & M \pm S D & M \pm S D & M \pm S D \\
\hline IQ & $92.11 \pm 10.2$ & $96.52 \pm$ & $100.26 \pm$ & $103.35 \pm$ \\
& & 12.3 & 11.1 & 11.6 \\
\hline VR & $91.13 \pm 13.3$ & $98.09 \pm$ & $102.30 \pm$ & $102.43 \pm$ \\
& & 15.0 & 12.0 & 14.5 \\
\hline VAR & $88.57 \pm 20.6$ & $94.39 \pm$ & $97.09 \pm$ & $103.43 \pm$ \\
& & 18.7 & 15.4 & 13.4 \\
\hline NR & $81.78 \pm 35.1 *$ & $95.61 \pm$ & $105.22 \pm$ & $108.76 \pm$ \\
& & 21.4 & 14.4 & 12 \\
\hline STM & $92.61 \pm 15.9$ & $94.80 \pm$ & $95.74 \pm$ & $96.72 \pm$ \\
& & 11.7 & 10.3 & 12.1 \\
\hline
\end{tabular}

$\mathrm{IQ}=$ Intellectual Quotient, VR=Verbal Reasoning, VAR= Visual Abstract Reasoning, NR= Numerical Reasoning, STM= Short Term Memory * Below average.

Table 4: Average scores of the intellectual quotient scale in IDM at $3,4,5$ and 6 years $(n=46)$.

Neurodevelopment and birth weight

For further analysis, the weight at birth was considered with the purpose of knowing what other factors influence in neurodevelopment. Based on the classification observed in table 2, the sample was classified into two groups. The first group had a birth weight equal to or less than $1500 \mathrm{~g}$ and the second group had a birth weight equal to or greater than 1501g; both groups consisted of 23 infants. Given that there was significance in the normality test and both groups had the same variance, the $t$ Student test was used to compare these groups.

The results are observed in table 5: for all assessments of IDM with a birth weight equal to or less than $1500 \mathrm{~g}$, there was a lower mean compared to IDM with a birth weight equal to or greater than 1501g, for both MDI and PDI, as well as IQ; however, a statistically significant difference was found only in the first year MDI, the group of IDM with a birth weight $\geq 1501 \mathrm{~g}$ being the one with a greater score $(M=97.48)$ compared to IDM with a birth weight of $\leq 1500 \mathrm{~g}(\mathrm{M}=86.26)$.

\begin{tabular}{|c|c|c|c|c|}
\hline & $\begin{array}{c}\leq 15000 g \\
(n=23)\end{array}$ & $\begin{array}{l}>1500 g \\
(n=23)\end{array}$ & $\begin{array}{c}\text { Student's t } \\
\text { test }\end{array}$ & $\mathbf{p}$ \\
\hline & $\mathbf{M}$ & $\mathbf{M}$ & & \\
\hline MDI 1 year & 86.26 & 97.48 & -2.214 & $.032^{*}$ \\
\hline PDI 1 year & 75.30 & 82.83 & -1.492 & .143 \\
\hline MDI 2 years & 80.91 & 88.04 & -1.322 & .193 \\
\hline PDI 2 years & 75.48 & 86.48 & -1.89 & .064 \\
\hline IQ 3 years & 91.48 & 92.74 & -.414 & .681 \\
\hline VR & 89.35 & 92.91 & -.905 & .370 \\
\hline VAR & 85.13 & 92.00 & -1.129 & .265 \\
\hline NR & 74.70 & 88.87 & -1.381 & .174 \\
\hline STM & 91.70 & 93.52 & -.384 & .703 \\
\hline IQ 4 years & 94.00 & 99.04 & -1.399 & .169 \\
\hline VR & 95.26 & 100.91 & -1.228 & .207 \\
\hline VAR & 90.26 & 98.52 & -1.511 & .138 \\
\hline NR & 89.65 & 101.57 & -1.942 & .059 \\
\hline STM & 93.87 & 95.74 & -.534 & .596 \\
\hline IQ 5 years & 95.48 & 105.04 & -3.177 & $.003^{*}$ \\
\hline VR & 98.39 & 106.22 & -2.309 & $.026^{*}$ \\
\hline VAR & 93.30 & 100.87 & -1.691 & .098 \\
\hline NR & 98.87 & 111.57 & -3.299 & $.002^{*}$ \\
\hline STM & 93.09 & 98.39 & -1.711 & .083 \\
\hline IQ 6 years & 98.65 & 108.04 & -2.951 & $.005^{*}$ \\
\hline VR & 96.57 & 108.30 & -2.962 & $.005^{*}$ \\
\hline VAR & 102.00 & 104.87 & -.721 & .475 \\
\hline NR & 104.04 & 113.48 & -2.868 & $.006^{*}$ \\
\hline STM & 93.65 & 99.78 & -1.753 & .087 \\
\hline
\end{tabular}

*Significance at 0.05. Note: MDI= Mental developmental index, $\mathrm{PDI}=$ psychomotor developmental index, IQ=

Intellectual Quotient, VR= Verbal Reasoning, VAR= Verbal Abstract Reasoning, NR= Numerical

Reasoning, STM= Short Term Memory.

Table 5: Student's t test for groups of IDM regarding weight at birth and neurodevelopment. 
Statistically significant differences were also found for IQ at 5 years of age for these same infants, with a t (44) $=-3.177, \mathrm{p}<0.05$, the group of IDM with birth weight $\geq 1501 \mathrm{~g}$ having higher scores $(\mu=105.4)$ compared to IDM with a birth weight of $\leq 1500 \mathrm{~g}(\mu=$ 95.48). The same sample at 6 years of age showed statistically significant differences in IQ between groups of IDM, $t(44)=-2.951$, $\mathrm{p}<0.05$, the IDM group with a birth weight of $\geq 1501 \mathrm{~g}$ obtained a higher score $(\mu=108.04)$ compared to IDM with a birth weight of $\leq$ $1500 \mathrm{~g}(\mu=98.65)$. Both the areas of Verbal Reasoning and Numerical Reasoning show significant differences, with better scores of IDM with a greater birth weight.

\section{Discussion}

Currently in Mexico, the number of cases of gestational diabetes is increasing, thus building a need for further investigation to face this situation. In spite of the increase in survival of the motherchild binomial thanks to advances in medicine, there is still controversy about neurodevelopmental outcomes of IDM [27].

The objective of this study was to describe neurodevelopment of IDM from the first to the sixth year using the same sample, in order to know the consequences due to a high neurological risk condition at birth.

In neurodevelopment it was found that the Motor Developmental Index is slightly below average during the first two years; nevertheless, as the child grows he/she can compensate for deficiencies as seen in this sample with a normal intelligence level at six years, which matches the results found by Nielsen., et al. [19] and Ornoy $[18,28]$, who explain that gestational diabetes may affect motor skills but not cognitive ability. Contrary to the results reported by Bolaños., et al. [14], who observed lower scores in graphic abilities in IDM through a school age assessment between the ages of 7 and 8 (these abilities are related to fine motor skills), in this sample this only occurred during the first two years. On his part, Ratzon., et al. [20] identified impairments in motor skills in IDM, though they found a relationship with control of the mother's glucose levels during pregnancy. By observing positive results in this sample, it can be inferred that mothers had a good control because they are women admitted to a third level hospital, and as soon as gestational diabetes was diagnosed had a constant monitoring. As Medina-Pérez [2] points out, one can expect a good prognosis when the mother has a daily monitoring of glucose levels, makes changes towards a healthy lifestyle, exercises and has a balanced diet.

Papalia and Martorell [29] consider that school children may have a better performance on IQ tests, being at three years of age when the child starts school; in this sample below normal scores were observed in two areas of IQ; Visual Abstract Reasoning and Numerical Reasoning. Visual Abstract Reasoning refers to handeye coordination, visual spacial integration and comprehension. Finding low scores in this sample of IDM could be consistent with the Mild Developmental Delay obtained in the Psychomotor Developmental Index during the first and second years of life; notwithstanding, at six years of age they have a normal score. The same occurs with Numerical Reasoning, observing a score below average only at three years, subsequently reaching a normal level at six years [2].

In the Short Term Memory area a normal level is observed at all ages, contrary to the low scores reported by Temple., et al. [15] between 6 and 12 years in Short Term Memory with the Wechsler scale. This questions the importance of continuing follow-up of these children at older ages, because short term memory is a cognitive function coupled with processes such as perception and attention, important for learning; nevertheless, the scores in children in this sample were normal.

There are birth factors such as a very low birth weight, prematurity and comorbidities that may have severe consequences in the infant's cognitive development [3], for this reason a comparative analysis was made between both groups, observing that in this sample $50 \%$ of IDM weighed less than $1500 \mathrm{~g}$ at birth, this being considered a high risk neurological factor by the WHO. Means were compared for MDI, PDI and IQ in infants weighing less than $1500 \mathrm{~g}$ with infants weighing more than $1501 \mathrm{~g}$.

Low scores were observed for MDI and PDI, as well as IQ for all ages in infants with a birth weight less than $1500 \mathrm{~g}$ compared to infants with a weight greater than $1501 \mathrm{~g}$. In this sample, the differences between the groups were observed in the Mental Developmental Index of the first year of life, as well as IQ at 5 and 6 years of age, specifically in the areas of Verbal Reasoning and Numerical Reasoning. Low scores in Verbal Reasoning could relate to the results found by Dionne., et al. [16], where the assessment of infants from 18 months to 7 years found difficulties in expressive language.

In spite of significant differences in IQ at 5 and 6 years for infants with a birth weight less than $1500 \mathrm{~g}$ compared to infants with a weight greater than $1501 \mathrm{~g}$, both have normal scores, matching the results found by Martinez-Cruz., et al. [30] in a sample of this same institution, where infants with a low birth weight have scores in the normal range. 
The newborn with a high neurological risk as compared to a healthy newborn, cannot ensure a normal pattern in his/her growth and development, and therefore needs to be assessed periodically in order to detect disorders and risk factors. The literature explains that in the first years the child's brain goes through amazing changes in its structure, which is shaped by the experience the infant has with his/her environment. Through this interaction is how the process of adaptation unfolds, this is no less what we call intelligence. Brain plasticity could explain the changes in these infants who were at high neurological risk and nevertheless may have an IQ within the normal range, as observed in this sample [31].

It is of outmost importance to understand that behavior observed in a social context, which can be defined as experiences acquired by children in their environment, is what allows structural changes in their brain [32]. Therefore it is important to mention that in this sample there was a good compliance to Pediatric Follow-up at INPer and that the efforts of the family to take responsibility and be consistent with appointments, has a positive impact in their child's neurodevelopment as supported by Clausen., et al. [21], Fraser., et al. [22], and Kowalcyk., et al. [33], who reported that a good neurodevelopment in IDM is the result of shared family characteristics such as educational level of the parents, more than conditions at birth.

In the family context of IDM, it can be observed that most come from extended, nuclear families, indicating support networks, or a diversity where the child can develop social abilities and may benefit, as the development of higher mental functions has its origin in social interaction. As signaled by Lev Vigotsky [34], learning stimulates and activates mental processes through the interaction with other people, mediated by language and in diverse contexts, and is internalized by the child for a subsequent self-regulation.

Due to the above, the task of the psychologist in development is to consider the complete context of the child's development in order to guide the family, intervene in behaviors and emotions that do not favor the child's neurodevelopment, lead towards better parenting practices and promote an optimal development [35].

Likewise, pediatric follow-up and interdisciplinary work have the objective of preventing damages and/or detecting risk factors that can harm neurodevelopment and providing timely intervention in any event, but not just the participation of different professionals is important, the participation of the family is essential.
The family will facilitate changes in the environment that will benefit the child's neurodevelopment; moreover, it is not just the interventions made by the professionals and the different experiences the family provides for the child, but the quality of these [36-38].

\section{Conclusion}

- Gestational diabetes is a phenomenon that is increasing in Mexico and it is necessary to further investigate the consequences on offspring's neurodevelopment in order to tackle it. Neurodevelopment in IDM needs surveillance to prevent damage, because it is a high neurological risk population.

- During the first two years, IDM have a Mild Developmental Delay in the Psychomotor Developmental Index. However, at 6 years they show a normal level Intellectual Quotient. Hence in this sample it was found that IDM have psychomotor developmental delays at early ages that do not interfere with the Intellectual Quotient at 6 years.

- Low scores were detected for MDI, PDI and IQ for all ages in IDM with a birth weight $\leq 1500 \mathrm{~g}$ compared to infants with a birth weight $\geq 1501 \mathrm{~g}$. The differences observed in the sample are seen in the Mental Developmental Index at the first year of life, as well as in IQ at 5 and 6 years of age. Both groups have normal IQ scores.

- The family plays an essential role in stimulation and is the main factor of change for an optimal development for their child; they are responsible for taking the children to their pediatric follow-up appointments and for making the changes for their benefit.

\section{Bibliography}

1. Confederación Nacional de Pediatría de México. "Manual neurodesarrollo y estimulación temprana en pediatría” (2014).

2. Medina-Pérez EA., et al. "Diabetes gestacional". Diagnóstico y tratamiento en el primer nivel de atención Med. interna México 33.1 (2007): 91-98.

3. Torres-Espínola FJ. "Efectos de la obesidad y la diabetes materna durante la gestación sobre el neurodesarrollo de los hijos". Tesis doctoral, Universidad de Granada: España (2016).

4. Álvarez MÁ and Wong A. "Neurociencias y comunidad: la oportunidad del neurodesarrollo". Psiencia Revista Latinoamericana de Ciencia Psicológica 2.1 (2010): 30-33.

5. Gutierrez E L., et al. "The importance of the neural development assessment in children aged less than 30 months in the Peru- 
vian context". Acta Médica Peruana 33 (2016): 304-308.

6. Carratalá E and Ilieva K. "Variables familiares relacionadas con el desarrollo cognitivo y comunicativo en el primer ciclo de educación infantile". Revista de Psicología Clínica con Niños y Adolescentes 6 (2016): 31-36.

7. Flores S. "La importancia de las pruebas para evaluar el neurodesarrollo de los niños". Boletín Médico del Hospital Infantil de México 37 (2013): 175-177.

8. Romo-Pardo B., et al. "Pruebas de tamizaje de neurodesarrollo global para niños menores de 5 años de edad validadas en Estados Unidos y Latinoamérica: revisión sistemática y análisis comparative". Boletín médico del Hospital Infantil de México 69 (2012): 450-462.

9. Aguilar MJ., et al. "Diabetes mellitus materna y su influencia en el neurodesarrollo del niño: revisión sistemática”. Nutrición Hospitalaria 32.6 (2015): 2484-2495.

10. Domínguez-Vigo P., et al. "Implicaciones del diagnóstico de diabetes gestacional en la salud futura de la mujer". Ginecología y Obstetricia de México 12 (2017): 775-784.

11. Ornoy A., et al. "Neurobehaviour of school age children born to diabetic mothers". Archives of Disease in Childhood-Fetal and Neonatal Edition 2 (1998): F94-F99.

12. Cordón M., et al. "Neural correlates of emotion processing in typically developing children and children of diabetic mothers". Developmental Neuropsychology 34 (209): 683-700.

13. Carreño J., et al. "Padecimientos crónicos maternos (diabetes o cardiopatías) y desarrollo infantil". Perinatología y Reproducción Humana 16 (2002): 80-87.

14. Bolaños L., et al. "Características neuropsicológicas en niños escolares nacidos de madres con diabetes gestacional". Revista Neuropsicología, Neuropsiquiatría y Neurociencias 7 (2007): 107-123.

15. Temple C., et al. "Cognitive function in 6-to 12-year-old offspring of women with Type 1 diabetes". Diabetic Medicine 28 (2011): 845-848.

16. Dionne., et al. "Gestational diabetes hinders language development in offspring”. Pediatrics 122 (2008): e1073-e1079.

17. Nomura Y., et al. "Exposure to gestational diabetes mellitus and low socioeconomic status: effects on neurocognitive develop- ment and risk of attention-deficit/hyperactivity disorder in offspring'. Archives of Pediatrics and Adolescent Medicine 166.4 (2012): 337-343.

18. Ornoy A. "Growth and neurodevelopmental outcome of children born to mothers with pregestational and gestational diabetes". Pediatric Endocrinology Reviews 3.2 (2005): 104-113.

19. Nielsen L., et al. "Maternal blood glucose in diabetic pregnancies and cognitive performance in offspring in young adulthood: a Danish cohort study". Diabetic Medicine 27 (2010): 786-790.

20. Ratzon N., et al. "Comparison of the motor development of school-age children born to mothers with and without diabetes mellitus". Physical and Occupational Therapy in Pediatrics 20 (2000): 43-57.

21. Clausen D., et al. "Cognitive function in adult offspring of women with gestational diabetes-the role of glucose and other factors". PLoS One 8 (2013): e67107.

22. Fraser A., et al. "Maternal diabetes in pregnancy and offspring cognitive ability: sibling study with 723,775 men from 579,857 families". Diabetologia 57 (2014): 102-109.

23. Vargas Rubilar JA and Filippetti VA. "La importancia de la parentalidad para el Desarrollo Cognitivo Infantil: una revisión teórica". (2014).

24. Veena R., et al. "Childhood cognitive ability: relationship to gestational diabetes mellitus in India". Diabetologia 53 (2010): 2134-2138.

25. Bayley N. "Bayley Scales of Infant Development". Second Edition. The Psychological Corporation (1993).

26. Thorndike R., et al. "The Stanford-Binet Intelligence Scale: Fourth Edition". The Riverside Publishing Company (1986).

27. Delgado-Becerra A., et al. "Morbidity in the infant of diabetic gestational mother, at the Instituto Nacional de Perinatologia Isidro Espinosa de los Reyes". Perinatología y Reproducción Humana 25.3 (2011): 139-145.

28. Ornoy A., et al. "School-age children born to diabetic mothers and to mothers with gestational diabetes exhibit a high rate of inattention and fine and gross motor impairment". Journal of Pediatric Endocrinology and Metabolism 14 (2001): 681-686.

29. Papalia D and Martorell G. "Desarrollo humano". México: Mc Graw Hill (2017). 
30. Martínez-Cruz CF., et al. "Association between intelligence quotient scores and extremely low birth weight in school-age children". Archives of Medical Research 37 (2006): 639-645.

31. Camacho T and Serrani M. "Neurodesarrollo infantil, pautas para la prevención del desarrollo y las alteraciones del desarrollo infantile". Argentina: Duken (2013).

32. Perinat A and Lalueza JL. "Psicología del desarrollo: un enfoque sistémico". Editorial UOC 83 (2007).

33. Kowalczyk M., et al. "Psychomotor development in the children of mothers with type 1 diabetes mellitus or gestational diabetes mellitus". Journal of Pediatric Endocrinology and Metabolism 15 (2002): 277-282.

34. Vygotsky LS. "Pensamiento y lenguaje”. Madrid: Paidós (1978).

35. Chavez T. "Desarrollo neonatal infantil. Un enfoque multi, inter y transdisiplinario para la prevención del daño". México: Panamericana (2003).

36. Carratalá E and Ilieva K. "Variables familiares relacionadas con el desarrollo cognitivo y comunicativo en el primer ciclo de educación infantile". Revista de Psicología Clínica con Niños y Adolescentes 3 (2016): 31-36.

37. López G and Guiamaro Y. "El rol de la familia en los procesos de educación y desarrollo humano de los niños y niñas. Ixaya". Revista Universitaria de Desarrollo Social 10 (2017): 31-55.

38. Mora A and Rojas L. "Estilo de funcionamiento familiar, pautas de crianza y su relación con el desarrollo evolutivo en niños con bajo peso al nacer". Revista Latinoamericana de Ciencias Sociales, niñez y juventud 3 (2005): 181-212.

\section{Assets from publication with us}

- Prompt Acknowledgement after receiving the article

- Thorough Double blinded peer review

- Rapid Publication

- Issue of Publication Certificate

- High visibility of your Published work

Website: www.actascientific.com/

Submit Article: www.actascientific.com/submission.php

Email us: editor@actascientific.com

Contact us: +919182824667

Citation: Jiménez-Quiroz Rosalía., et al. "Assessment of Neurodevelopment of Infants of Diabetic Mothers 6 Year Follow-up". Acta Scientific Women's Health 3.4 (2021): 10-19. 